\title{
A LÓGICA DA IMAGEM PICTÓRICA
}

\author{
O JOGO DO BELO E DO FEIO
}

de José Arthur Giannotti. São Paulo: Companhia das Letras, 2005.

ALBERTO TASSINARI

O jogo do belo e do feio baseia-se numa sutil e elaborada concepção da imagem pictórica. Como outros livros de Giannotti, não é um livro fácil. As dificuldades de leitura e compreensão, porém, não têm origem em nenhuma deficiência de exposição do autor. Giannotti pensa, muitas vezes, nos limites do pensável. São os temas que elege para pensar e o rigor com que se põe a abordá-los que o levam a passagens em que a luta com as palavras parece vã. Some-se a isso que o livro atual trata do escorregadio conceito de beleza e o leitor se verá às vezes meio a esmo no que se deixa pensar apenas de viés. Mas para que fiquem assinaladas as qualidades de exposição de Giannotti, que o leitor se detenha em uma das tantas análises que ele promove sobre determinadas obras de arte. Clareza, sutileza, expressividade e generosidade ali estão. Não menos generoso, porém, é se arriscar por caminhos ainda não trilhados para a construção de uma estética da pintura. E são tantos os conceitos envolvidos na sua construção que é difícil saber por onde começar uma explanação do tema, ainda que breve. Em grande parte são conceitos de matriz wittgensteiniana. Ao articulá-los de um modo peculiar e para que possam mostrar uma pintura como um jogo de linguagem - sendo esse o mais importante conceito emprestado do pensamento de Wittgenstein -, o livro também tece, por sua vez, um jogo de linguagem filosófico instigante e engenhoso.

Não sei se é de todo correto abordar um livro de filosofia como um jogo de linguagem. Parece-me que sim. Se uma pintura, como se depreende de $O$ jogo do belo e do feio, pode ser compreendida como um jogo de linguagem não-verbal que almeja a beleza, já um livro de filosofia, na sua maneira de concatenar uma diversidade de conceitos, será um jogo de linguagem que busca o conhecimento. Giannotti, assim, ao articular conceitos para capturar a beleza na pintura, também acaba por inventar os meios para filosofar a respeito. Pois Ojogo do belo e do feio é antes de tudo um livro de filosofia, um livro de invenções conceituais e, mais especificamente, de estética - coisa rara no contexto filosófico brasileiro. Entretanto, as dificuldades de compreensão assinaladas, 
receio, talvez me impeçam de passar uma visão clara do livro. É que não é fácil distinguir, pelo menos para mim, diante de certos malentendidos durante a leitura, se se trata de não entender o que é dito ou se é o caso de não se entender com a forma de pensar de Giannotti. Diante dessa sobreposição, as condições dessa resenha, devo reconhecer, são bastante interpretativas, pois, na tentativa de entender a obra, muitas vezes a entendi preenchendo vazios de entendimento com as partes que pude assimilar.

1

Se o conceito de jogo de linguagem é o mais importante dos conceitos mobilizados para a construção do que pode ser compreendido como uma lógica da imagem pictórica, talvez seja mais proveitoso, entretanto, começar a desenhar um esboço de O jogo do belo e do feio por um conceito mais simples e também de origem wittgensteiniana: o conceito de ver como. É por sua diferença com o ver que o conceito pode ser mais bem explicado. Ao conceito de ver corresponde o uso mais habitual que fazemos do verbo "ver". Se duas pessoas olham nuvens no céu e uma pergunta à outra o que vê, a resposta mais freqüente costuma ser: "vejo nuvens". O interlocutor insiste, então, se não é possível ver em determinada nuvem um elefante. A resposta então poderá ser: "sim, vejo um elefante na nuvem". Ninguém, porém, ao pé da letra, é capaz de ver um elefante numa nuvem. Elefantes não voam... Já a resposta "vejo a nuvem como um elefante" elimina a impossibilidade de ver na nuvem o que não pode ser visto enquanto tal, mas que pode, certamente, ser visto como uma figura. Resumindo e simplificando: ver a nuvem e ver a nuvem como um elefante são dois modos de ver distintos, embora relacionáveis. E, sendo distintos, correspondem a conceitos e usos distintos do verbo "ver". Se concebermos a superfície de uma pintura como um conjunto de linhas e cores arranjados numa certa ordem - mais ou menos como Maurice Denis a definiu - e nela só vermos linhas e cores, estaremos vendo apenas a superfície da pintura. Mas se ao ver as linhas e cores também for possível as ver como uma batalha, estaremos vendo linhas e cores como o episódio de uma guerra. Toda imagem pictórica exige, então, que se saiba ver o que se configura na sua superfície como coisas e seres distintos da sua configuração no plano pictórico. Observação que pode parecer banal, pois, em geral, o olhar do espectador dirige-se, ao ver uma pintura, logo para a batalha ali exposta, para seguir com o mesmo exemplo, e não para a superfície do quadro. Mas é de sutis distinções sobre coisas banais que também se faz boa filosofia. E de fôlego e inventividade para concatená-las.

Se a imagem pictórica é, de um lado, linhas e cores num certo arranjo e, de outro, linhas e cores vistas como seres e coisas, pouco se terá andado, ainda, em direção às condições que nos levam a dizer se uma pintura é bela ou não. Mas a trilha já está aberta, pois é no jogo entre o 
ver e o ver como que essas condições começam a se desenhar. Mas outras distinções são necessárias. Ao arranjo de linhas e cores corresponde o que Wittgenstein chama de meios de apresentação de um jogo de linguagem. São também sinais. E sinais nada significam enquanto não se transformam em signos, ou seja, enquanto não for possível ver o sinal como algo diferente dele e que representa esse algo diferente. Enquanto não for possível, ainda seguindo com o exemplo, ver as linhas e cores da pintura como uma batalha. Tem-se assim, numa imagem pictórica, de um lado, meios de apresentação transformados em representações e sinais transfigurados em signos e, de outro, os representados das representações e os significados dos signos. Ao primeiro lado da imagem pictórica Giannotti chama "imagem". Ao segundo, o "imageado". É nas relações entre a imagem e o imageado que o jogo entre o que é belo ou feio é decidido. Mas novas distinções devem ainda entrar em campo. Se o imageado resulta do ver como da imagem, se uma batalha só é vista na pintura porque os sinais apresentados na imagem se deixam ver como signos e representações de uma batalha, então o que é visto enquanto representado está na inteira dependência do modo como a imagem é construída. A imagem, desse modo, não é uma cópia ou imitação do imageado, pois este último só existe por meio do modo como os sinais se apresentam e se configuram na imagem. Ao modo de configurar os sinais corresponde um método de projeção, tomando Giannotti de empréstimo, aqui, mais um conceito de Wittgenstein.

A expressão "método de projeção" é bastante feliz. Enquanto traça e pigmenta sinais, o pintor tem em vista o que neles vê, mas também, por meio deles, o que é possível projetar e ver como signos ou representações desses sinais. Se um traço que é para se ver como um sorriso melancólico se alegra, o pintor o corrigirá. E o que acontece para cada parte da pintura acontece também para a relação entre elas. $O$ trabalho de construção da imagem, e da qual o imageado é pura conseqüência, tem sempre em vista, assim, tanto a relação entre os sinais quanto a transformação dos sinais em signos e representações. O imageado, assim, é apenas o representado de seres e coisas. Não pode apresentálos em carne e osso. O quadro de uma batalha ou de uma mulher não é uma batalha ou uma mulher. É apenas através dos meios de apresentação, apenas pelo arranjo de linhas, cores etc., que o imageado é visto. Entre linhas apresentadas na imagem e as mesmas linhas que representam o representado, por exemplo, um rosto, surge uma relação que está, desse modo, na inteira dependência do método de projeção. Se ao ver as linhas é possível as ver como um rosto, o método de projeção é que decide se a linha será contínua ou quebradiça, grossa ou fina, sinuosa ou retilínea, e assim por diante. O conceito de ver como se encontra, aqui, com um outro que é praticamente a sua tradução: o de visão de um aspecto. Sempre que vejo algo, no caso, linhas, como outro algo, no caso, um rosto, o segundo é um aspecto do primeiro. Aspecto porque não me deixa ver apenas o primeiro enquanto tal, não me deixa ver 
somente linhas, mas me leva a ver linhas como um rosto. Dito ainda de outra forma, as linhas ganham o aspecto de um rosto. Mas esse rosto, por sua vez, como o vejo na sua fisionomia? É grave ou alegre? Sereno ou caricato? Esse segundo ver como, se assim pode ser dito, não tem nada de misterioso. $O$ rosto é visto como alegre ou triste porque, primeiro, as linhas deixam ver um rosto e, segundo, deixam ver um rosto conforme as linhas se apresentam no método de projeção. As linhas, ao se deixarem ver como um rosto, também só podem se deixar ver como um rosto alegre, triste ou neutro. Não há algo como um rosto em geral numa imagem pictórica. Se é que há em algum lugar.

Se um rosto deve ser visto como alegre ou triste numa determinada pintura, essa é uma escolha do pintor. Mas se acontece de um rosto se mostrar alegre quando o restante da pintura, e em geral também a escolha do pintor, pediam um rosto triste, então há algo inadequado na pintura. Inadequação, porém, que não está nos sinais e nos meios de apresentação do método de projeção. Estes cumpriram sua parte, embora o resultado tenha sido contraditório. Nunca há nada de inadequado nos sinais que resultam em representados desse ou daquele modo. A inadequação está em deixar ver um imageado alegre quando deveria ser triste. É no jogo entre a imagem e o imageado, desse modo, que a inadequação se mostra, ou, ainda, no jogo entre sinais e os significados dos signos, entre meios de apresentação e os representados das representações. Mas sinais, repetindo, antes de poderem ser vistos como signos, não são adequados ou inadequados. Já signos que são passíveis de representar tanto uma situação quanto a negação dessa situação se encaixam em representações que Wittgenstein chama bipolares. E com isso se quer dizer que o signo de um rosto numa pintura pode ser alegre ou pode ser triste e, mais ainda, pode ser adequado se mostra-se alegre quando espera-se que se mostre alegre ou triste quando espera-se que se mostre triste, mas será inadequado se a tristeza esperada for alegre ou a alegria que se espera, triste. Há, desse modo, uma lógica do signo visual, pois a transformação do sinal em signo pode ser correta ou incorreta. Mais ainda, surgem elos de necessidade entre os signos, pois o que deve ser mostrado alegre ou triste depende do restante do quadro. Uma pintura como um todo pode ser dita, assim, correta ou incorreta, adequada ou inadequada. Não seria o caso de chamá-la verdadeira ou falsa? Aqui é preciso distinguir, porém, entre o tipo de necessidade a que uma imagem pictórica atende e aquele pretendido pelo conhecimento. A tristeza ou a alegria de um rosto numa pintura não corresponde, em geral, a uma correção ou incorreção em relação a um fato. Sua adequação ou inadequação diz respeito à expressão que deve ter em relação ao restante da pintura. Essa não é uma cópia do mundo, mas transformação expressiva do mundo.

De que maneira, porém, alguém julga a adequação ou inadequação expressiva de parte ou do todo de uma pintura? Continuemos com o 
exemplo do rosto alegre ou triste e o imaginemos por uma figura bem simples. Nesse caso, a curva que será vista como um sorriso alegre ou triste no rosto possui posições invertidas. Há assim uma regra que ensina, ainda que meu exemplo seja bem singelo, a desenhar um sorriso alegre ou triste. Uma regra que não é individual, mas coletiva, e que pode ser ensinada. Aquele que a aprendeu poderá seguir a regra. Uma pintura possui assim uma lógica, pois pode ser compreendida como resultado de um conjunto de regras que transformam sinais visuais em signos visuais. O conceito de jogo de linguagem tem bem esse jeito, o de um conjunto de regras que se segue e que se pratica para transformar sinais em signos, meios de apresentação em representações. Já os sinais visuais que obedecem a regras de execução com o intuito de poderem ser vistos como signos visuais expressivos podem ser compreendido como um jogo de linguagem não-verbal, pois as regras não se aplicam a sinais da língua falada ou escrita, mas a sinais visuais que vemos como signos, por sua vez, de coisas também a ver. Entretanto, se bastasse a execução correta de regras de um jogo de linguagem não-verbal para realizar uma bela pintura, a lógica da imagem pictórica se assemelharia à de uma disciplina prática como, por exemplo, à do desenho técnico, que antes exigia dedicação, mas não invenção, de seus praticantes, $e$ que hoje vem, por assim dizer, já embutida nos programas e controles de um microcomputador. A beleza de uma pintura não está apenas na sua lógica, mas numa lógica que se mostra ao mesmo tempo em que inventa regras novas. E regras que também almejam uma correção expressiva.

Como se dá essa visão das novas regras expressivas quando julgamos bela uma pintura? Aqui é o momento para resumir três contribuições, ou inventos, de Giannotti para a construção de uma estética de matriz wittgensteiniana. A primeira delas é que toda imagem pictórica é um jogo de ver e de ver como. Mesmo que o olhar do espectador logo se atenha ao imageado, este só existe como função de ver a imagem como imageada. Ou seja, o imageado e a expressividade que ganha numa pintura é algo inteiramente construído pela imagem, pelo arranjo de seus sinais. A pintura cria, amplia e transfigura significados habituais do mundo. Não os repete, não copia o mundo. E, mais importante, as regras pelas quais cria não são em nada misteriosas e inefáveis, mas invenções que surgem da prática da fabricação de sinais, de suas relações e também das relações que remetem ao imageado. A segunda contribuição, a mais importante, é a junção, apenas esboçada nesta resenha, que Giannotti promove de inúmeros conceitos de Wittgenstein para compreender a arte da pintura. Essa junção não foi feita nem por Wittgenstein nem, salvo engano, pela estética de língua inglesa dos últimos 50 anos. Fortemente influenciada pelo pensamento de Wittgenstein e portadora do seu legado estético, sua índole é mais parcimoniosa. Costuma se deter em um ou outro momento de seu pensamento, mas não numa síntese de inúmeros conceitos. A ter- 
ceira contribuição é a ênfase na distinção entre ver e ver como não apenas para a concepção da imagem como uma construção da qual o imageado é pura conseqüência, mas também na importância que adquire, compreendidos os demais conceitos em cena, para a compreensão da pintura bela.

O ponto é crucial e vale a pena deter-se nele. Se são novas regras numa determinada pintura que a tornam bela, inventiva, é porque sinais e meios de apresentação também novos levam a vê-los como signos e representações novos. Mais ainda, os sinais são vistos como aspectos novos do imageado. Ao trabalhar novas regras no método de projeção da imagem, o pintor ocasiona no imageado mudanças de aspecto. O conceito de mudança de aspecto, até aqui não comentado, se torna então preponderante. Se o conceito de ver como encontra, como antes dito, uma tradução no conceito de visão do aspecto, já o de mudança de aspecto mostra a passagem entre o ver e o ver como de um modo evidente. Evidência que convém explicar. Não é evidente, por exemplo, que, ao olhar uma fotografia, eu veja o fotografado como o imageado da imagem fotográfica. Sei que aquilo que vejo na fotografia, que se pense numa foto caseira e amadora, só o vejo pela fotografia, mas não atento em nenhum momento para a transformação da imagem em imageado. Há pouca expressividade nas fotografias desse tipo. Numa pintura, porém, os meios de apresentação são densos e me levam, por exemplo, a ver uma linha como um rosto sem deixar de ser linha, ou, ainda, quase que posso assistir à transformação da linha em rosto e vice-versa. Esse "quase", porém, essa quase-evidência ainda não diz tudo do conceito de mudança de aspecto. Há imagens ambíguas, como aquela em que vemos ora como um pato e ora vemos como um coelho, necessariamente alternando-os, que exemplificam bem o conceito de mudança de aspecto. Transposto para a imagem pictórica, esse conceito corresponde aos momentos mais expressivos da pintura e por meio dos quais vemos os sinais (cores, linhas etc.) como signos e vice-versa. Vemos tinta virar carne e carne voltar a tinta, por exemplo. Esses momentos mais expressivos em relação às demais partes da pintura, estas já ligadas de um modo necessário, surgem, no que se destacam, como diferenciados das demais. A pintura bela, assim, é aquela em que cada parte se amarra à outra de um modo necessário, mas também é aquela em que certos momentos trazem uma necessidade nova, uma expressão mais contundente e que se tornam, assim, momentos que modificam toda a pintura. O selim e o guidão de bicicleta que Picasso transforma na carcaça de uma cabeça de touro muda o aspecto do selimguidão em touro, mas a operação inversa também é possível, embora não com a contundência da imagem ambígua pato-coelho, pois mesmo vendo o selim e o guidão, a imagem da carcaça não se elide por completo. Uma pintura bela, grosso modo, possui inúmeros sinais que se regulam de modo necessário e outros tantos em que os meios de 
apresentação se comportam como o selim-guidão de Picasso. Esse excesso de expressão, se assim pode ser dito, faz de uma pintura bela algo inesgotável no que dela podemos dizer. Assim como a beleza, para Kant, dá muito o que pensar, em Giannotti a bela pintura dá muito o que dizer. Sendo um jogo de linguagem não-verbal, nem por isso existe separadamente dos outros jogos de linguagem.

\section{2}

O esquema de uma pintura bela rascunhado acima encontra apoio, creio, na magnífica descrição que Giannotti nos fornece da Vista de Delft de Vermeer. Mas o que exatamente na pintura de Vermeer se ressalta de modo novo e mais expressivo em relação ao restante? Como nos mostra a compreensão do quadro por Giannotti, não há um só e único tipo de mudança de aspecto que responde pela expressividade da pintura. Se tomarmos o aspecto sombrio de certas coisas somos levados a ver os luminosos. Se nos detemos nos efeitos de luz, logo também paramos o olhar, estático e extasiado, num trecho de muro colorido. Não pretendo dar uma paráfrase de uma descrição tão feliz da pintura. Meu intuito é introduzir um novo conceito para fechar a figura do que seja uma bela pintura segundo Giannotti. Tal conceito, o de variação de aspectos, é, salvo engano, do próprio Giannotti, e não de Wittgenstein. Ele enriquece o conceito de mudança de aspecto assim como esse já enriquecia o de visão de aspecto. Na variação de aspectos o que está em jogo é aquilo que varia em determinados elementos da pintura quando uma mudança de aspecto se transfere de um elemento para outro. É assim que os aspectos sombrios da pintura se obscurecem ainda mais, quase se elidem, quando a pintura é vista como cor e, mais ainda, como cor luminosa, como quando o olhar se detém num trecho de muro colorido - ou no pequeno trecho de muro amarelo descrito por Proust, e retomado por Giannotti. Já quando o olhar o abandona e passeia pelas águas escuras do rio, os reflexos de luz na água fixam o muro como um de seus horizontes. Tanto o muro quanto a água escura variam, assim, seus aspectos conforme o olhar se fixa em um ou se espalha pelo outro. E, mais importante, o muro varia menos sua luminosidade do que as águas do rio e estas se elidem mais do que a forma do muro. Há uma dinâmica na pintura, desse modo, que muda por inteiro seu aspecto conforme se olha isso ou aquilo. O imageado torna-se problemático, contraditório. A fixação do olhar no pequeno trecho de muro amarelo não levou Proust, e Giannotti o segue, a vê-lo como se fosse uma pintura e uma beleza separadas do restante da pintura? $\mathrm{O}$ mesmo não ocorre com as águas escuras do rio. É essa luta numa pintura, promovida pela variação de aspectos, na medida em que o quadro e certos elementos são mais isso e menos aquilo conforme uma mudança de aspecto predomina, que leva Giannotti a dizer que toda arte é sublime. O imageado já não é mais algo, mas um entrecruzar-se sem fim de variações de aspectos. 
Não deixa de ser estranho, porém, uma investigação sobre o belo concluir que a beleza é sublime. Mas sobre isso Giannotti nos alerta desde o início do livro. Onde se diz "belo" é possível dizer "bonito", "big", "putz" e assim por diante. O belo, se pode ser dito "putz", além de um juízo será uma exclamação. E assim também me parece. Mas uma coisa é exclamar diante do belo e outra diante do sublime. E outra, ainda, diante do que é arte, tema para o qual Giannotti também aponta no início de $O$ jogo do belo e do feio. Mas se assim for, se as exclamações forem apenas sinais de acordo ou desacordo com a expressividade de uma obra, os usos das palavras "belo", "sublime" e "arte", parafraseando Wittgenstein, são aposentados. O problema, porém, me parece outro. E a sinonímia proposta entre diferentes palavras não o resolve. Ao examinar o belo ou o sublime na pintura, a investigação de Giannotti se move dentro de limites que são impostos pela limitação, por sua vez, de sua concepção de imagem. Embora sutil e rigorosa quando se trata da pintura figurativa - e sutil a ponto de mostrar que uma pintura bela como que explode seu imageado pela variação de aspectos -, o mesmo não ocorre quando trata da pintura abstrata. $\mathrm{Ou}$, dito de outra forma, é essa mesma sutileza que leva a ver a pintura abstrata como um caso limite da identidade contraditória do imageado. Na pintura abstrata, para Giannotti, a identidade das coisas se perde e o imageado se transforma em vicariedade.

Assim como Gombrich, que formulou uma teoria da arte, não uma estética, em tudo moderna - na qual o imageado também é puro resultado da imagem -, mas capaz de dar conta apenas da arte figurativa, a estética de Giannotti enfrenta o mesmo limite. Embora as concepções da imagem de cada pensador sejam muito divergentes mesmo porque um visa a história da arte e o outro, a estética -, não deixa de ser digno de nota que ambos se compliquem quando se deparam com obras de Mondrian. Gombrich, em Arte e ilusão, procura sinestesias musicais em Mondrian para garantir uma referência, ainda que musical, que a obra lhe parece negar visualmente. Em Ojogo do belo e do feio, Giannotti busca, numa pintura de Mondrian, resquícios de um imageado num jogo de sobreposições de quadrados. Diante de sua descrição de uma pintura de Mondrian, comparada com a de Vermeer, fica-se entre a alternativa de uma decadência brutal da arte holandesa ou dos limites de sua concepção da imagem. Pois, afinal, por que ao ver o imageado de uma imagem, por que ao ver a imagem como um imageado, é preciso ter a fisionomia, ainda que construída e problemática, de uma coisa ou de um ser? Para a arte figurativa, isso é necessário. Mas as descrições logo se enriquecem com as relações entre as coisas, com qualidades que possuem e assim por diante. A arte abstrata não é a arte figurativa menos as coisas. A arte figurativa é que é a arte abstrata mais as coisas. Esse não me parece um problema incontornável para a estética de Giannotti, mas é, por enquanto, um capítulo não escrito. E se toco no ponto é também para salientar que a dificuldade enfrentada 
com a arte abstrata se transforma numa dificuldade ainda maior quando o juízo "isso é belo" é substituído pelo juízo "isso é arte". Que tipo de expressividade deve ter uma obra contemporânea para que possamos dizer que ela é uma obra de arte? Pois a questão contemporânea é a da bipolaridade entre a arte e a não-arte. E uma segunda reformulação da concepção de imagem de Giannotti se faz necessária. Se para julgar uma pintura bela não necessito a ver como bela, mas sim como uma rede de variações de aspectos expressivos, talvez seja possível encontrar um caminho em que o jogo do ver e do ver como, para simplificar os conceitos de Giannotti, possam ser usados tanto para aprofundar a compreensão da arte abstrata quanto a da questão contemporânea da arte e da não-arte.

Ojogo do belo e do feio é um livro sobre pressupostos do juízo estético. Nessa condição, sua validade se mede não só por sua coerência interna, que é notável, mas também pelas dimensões que abre ou fecha para uma compreensão da arte e de sua história. Em relação à arte abstrata, a porta já está entreaberta. Em relação à arte contemporânea, com exceção de certas obras figurativas, a porta está fechada. Quando Giannotti assinala que suas descrições de obras podem não diferir muito das dos críticos ou historiadores de formação fenomenológica, mas que, quanto a pressupostos, a divergência é grande, cabe então, creio, perguntar pelas vantagens que sua concepção oferece em relação às demais com que compete. Cabe perguntar, entre outras coisas, pela abrangência histórica que alcança. E a arte contemporânea, a arte dos últimos 50 anos, dado que ela é a arte de nossos dias, tem, por sua vez, um interesse especial dentro da história da arte. Ojogo do belo e do feio tem, assim, alcance histórico apenas até meados da década de 50 . E mesmo no período da primeira metade do século, seu alcance é parcial, pois a arte abstrata surge no livro como um tema limite e acanhado. O que não significa que uma compreensão da arte figurativa como a levada a termo por $O$ jogo do belo e do feio não possua mérito. Possui. E muitos. Como também possuem a de todos os filósofos que Giannotti critica e a todos engloba sob a categoria de pensadores que concebem a relação entre a imagem e o imageado como imitação. Nisso, não compreenderam a distinção entre ver e ver como e, na mesma trilha, muitos privilegiaram, o que é fato, o imitado como origem da beleza ou artisticidade da arte.

Para ficar apenas num exemplo, que se tome o de Merleau-Ponty. Para este, a diferença entre a visão que Cézanne tinha de seu motivo, ou seja, do imitado, e a pintura do mesmo, ou seja, a imagem, é irrelevante. Irrelevância, é verdade, que não poderia se basear numa confusão, por Merleau-Ponty, entre um quadro e uma montanha ou maçãs. O erro, seé que existe, se justifica pela tentativa de compreender filosoficamente a percepção como expressão e, dado que uma pintura também fornece uma imagem expressiva para a percepção, nisso confluir a linguagem filosófica com a da pintura. É uma tentativa 
criticável, como tudo, aliás, mas não isenta de coerência dentro da obra de Merleau-Ponty. Além disso, ao elaborar uma ontologia do visível, ele postula a profundidade da percepção, e de uma pintura, como o invisível do visível, como aquilo que não vemos, mas que é possibilidade do ver. E como se trata de uma ontologia, a profundidade é interpretada como o ser que se oculta ao se revelar nas coisas dispostas espacialmente para quem percebe. O resumo é muito breve, mas tem apenas dois intuitos. Primeiro, concorde-se ou não com MerleauPonty, sua obra dá conta de fundamentar a arte moderna figurativa e também a abstrata, visto que para compreender esta última basta a existência de sinais em profundidade. Mas dado que a profundidadé um tema do qual sua filosofia não pode separar-se, ela encontra limites históricos diante da pintura contemporânea, na qual um quadro não é mais uma imagem. Nesse sentido, e esse é o segundo intuito, o pensamento de Giannotti não cobre um espaço histórico diferente do de Merleau-Ponty. As diferenças ficam apenas nos pressupostos. E numa batalha pelos pressupostos, deve-seescolherOjogo do belo ou dofeio ou Olho e o espírito? Para quem se interessa, como eu, tanto por filosofia quanto pelos pressupostos de conceitos que compreendam a arte contemporânea, trata-se de uma falsa escolha. Ambas as obras movimentam o pensamento. E também as de Heidegger e Gadamer, as de Benjamin e Adorno, e as de outros filósofos criticados por Giannotti. A crítica de pressupostos faz sentido, creio, pelos campos que abre e pelos que fecha. Há os que necessitam ser abertos e há os que precisam ser fechados. Mas se há sobreposição dos objetos estéticos históricos, a escolha é uma questão de gosto filosófico ou, ainda, de formas de vida - aceitando-se que o conceito wittgensteiniano de forma de vida admita o plural. E uma forma de vida não é verdadeira nem falsa.

ALBERTO TASSINARI, doutor em filosofia pela USP, é autor de "O espaço moderno" (Cosac Naify). 